\title{
A constituição do símbolo e o processo analítico para Winnicott
}

\author{
Leopoldo Fulgencio ${ }^{1}$ \\ Pontifícia Universidade Católica de Campinas, Campinas-SP, Brasil
}

\begin{abstract}
Resumo: Neste artigo pretende-se mostrar que, para Winnicott, o fundamento do processo de simbolização está na atividade que caracteriza a expansão da área dos fenômenos transicionais. Enquanto para Klein, a relação com objetos que são símbolos de outros objetos ocorre como defesa contra a angústia derivada das relações objetais, para Winnicott, esta relação deriva da atividade do brincar e da criatividade a ela associada. Essa diferença caracteriza a maneira como cada um desses autores concebe a entrada do homem na vida cultural, e como eles concebem os objetivos do método de tratamento psicanalítico.
\end{abstract}

Palavras-chave: símbolo, Klein, Melanie, ansiedade, Winnicott, Donald Woods, recreação.

\section{The constitution of the symbol and the analytical process according to Winnicott}

\begin{abstract}
We intent to show that, for Winnicott, the base of the symbolization process is in the activity that characterizes the expansion of the area of transitional phenomena. Melanie Klein considers that the relation with objects that are symbols of other objects occurs as a defense strategy against anxiety that results from object relations, while for Winnicott, this relation derives from the play activity and creativity associated to it. This difference characterizes the way each of the authors conceives the entering of the human being in cultural life and how they conceive the objectives of the psychoanalytical treatment method.
\end{abstract}

Keywords: symbol, Klein, Melanie, anxiety, Winnicott, Donald Woods, recreation.

\section{La constitución del símbolo y el proceso analítico para Winnicott}

\begin{abstract}
Resumen: En este artículo, tengo la intención de mostrar que, para Winnicott, el fundamento del proceso de simbolización se encuentra en la actividad que caracteriza la expansión del área de los fenómenos transicionales. Mientras para Klein, la relación con objetos que son símbolos de otros objetos se produce como defensa contra la angustia que resulta de las relaciones con los objetos, para Winnicott, esta relación resulta de la actividad de jugar y de la creatividad asociada a ella. Esta diferencia caracteriza la manera cómo cada uno de los autores concibe la entrada del hombre en la vida cultural, y como conciben los objetivos del método de tratamiento psicoanalítico.
\end{abstract}

Palabras clave: símbolo, Klein, Melanie, ansiedad, Winnicott, Donald Woods, recreación.

O processo de desenvolvimento afetivo e cognitivo, compreendido do ponto de vista da psicanálise, corresponde a um dos aspectos fundamentais para entender a constituição do ser humano. A maneira como cada uma das perspectivas teóricas clássicas (Freud, Klein, Bion, Lacan e Winnicott) compreende esse processo é fundamental tanto para a teoria quanto para a prática clínica, em especial no tratamento daqueles pacientes que tiveram ou têm problemas significativos para entrar no mundo simbólico. No caso do tratamento de crianças, esse aspecto torna-se ainda mais central, dado que é justamente no trato das atividades expressivas da criança (simbólicas e não simbólicas) que se encontram a matériaprima e a maneira de intervir no seu tratamento, contribuindo para que possam desenvolver-se em direção à conquista do mundo simbólico.

Neste artigo, será feito um estudo teórico explicitando as concepções de Melanie Klein e Donald Winnicott sobre o processo de constituição do símbolo e sua relação com a prática clínica. Essa opção está notadamente marcada pela

\footnotetext{
${ }^{1}$ Endereço para correspondência:

Leopoldo Fulgencio. Rua Marcos de Azevedo, 93. CEP 05.428-050. São

Paulo-SP, Brasil. E-mail: leopoldo.fulgencio@gmail.com
}

importância da obra de Winnicott, na história de desenvolvimento da psicanálise (Abram, 2008; Fulgencio, 2007; Loparic, 1997, 2001; Phillips, 1988). O caminho de leitura e de interpretação que especifica os textos e o modo de interpretá-los, tanto de Klein como de Winnicott, será explicitado a seguir, antes de se dedicar a suas análises.

Antes de analisar como se conquista a possibilidade de estabelecer relações simbólicas em Winnicott e Klein, é necessário que se esteja de acordo sobre o que é um símbolo. Será considerado como definidor do que é um símbolo a proposição do semiótico Charles Sanders Peirce que caracteriza o símbolo como um tipo de signo. Para este autor, um signo é uma coisa (o próprio signo) no lugar de outra (seu objeto ou referente) para alguém (seu interpretante) (Peirce, 1975). Uma das maneiras de classificar os signos é considerar o tipo de relação que existe entre ele e seu referente: se a relação é de semelhança (uma "cópia", por assim dizer, do referente), então ele o classifica como um ícone; se a relação é de causa e efeito (onde há fumaça há fogo, por exemplo, a fumaça no lugar do fogo), trata-se de um índice; e se a relação entre o signo e o referente é arbitrária (um convenção, uma palavra, qualquer outro tipo de conexão não indicial nem icônica), então é um símbolo (Peirce, 1975). Essa definição semiótica do símbolo servirá como referência de apoio para determinar 
o que será considerado aqui um símbolo ou uma relação simbólica com os objetos do mundo.

É bom explicitar o motor do processo de simbolização, diferenciando as posições de Klein e Winnicott. Para atingir esse objetivo, há o seguinte desenvolvimento: (1) análise do artigo de Klein (1930/1996) "A importância da formação de símbolos no desenvolvimento do ego", mostrando como ela concebe o desenvolvimento das equações simbólicas e considerando que estas são produzidas como mecanismos de defesa contra a angústia nas relações de objeto, e que isso contribui para o desenvolvimento do ego, bem como para a entrada do homem na vida grupal e cultural; (2) análise do artigo de Winnicott (1953/1975a) "Objetos transicionais e fenômenos transicionais", demonstrando que a raiz e o fundamento do processo de simbolização está na experiência com objetos transicionais, impulsionado pela possibilidade de esses objetos serem paradoxalmente criados e encontrados, e que a expansão dessa área da transicionalidade e da atividade de brincar tornará possível o processo de simbolização e dará as condições para o desenvolvimento saudável do eu, e para a entrada do homem na vida grupal e cultural; (3) explicitar uma das diferenças entre Klein e Winnicott no que diz respeito ao método de tratamento psicanalítico, opondo a análise da angústia ao brincar compartilhado como télos do processo analítico.

\section{Klein, a formação de símbolos e o desenvolvimento do eu}

Para Melanie Klein, a criança, desde seu início mais remoto, já tem a possibilidade de estabelecer relações com objetos que ela reconhece como sendo diferentes dela, estabelecendo com eles uma série de relações afetivas, tais como amor, ódio, fantasias, ansiedades e defesas (Klein, 1952/1991a). Isso significa que há, como condição de possibilidade para que uma relação de objeto possa ocorrer, tanto um ego que pode se relacionar quanto o reconhecimento de objetos externos (ainda que não reconhecidos na sua totalidade, ou seja, ainda que sejam objetos parciais). Dessas relações com objetos surgem angústias e, consequentemente, são colocados em funcionamento mecanismos de defesa contra elas, seja no caso da dinâmica esquizoparanoide - em que o amor e o ódio são vividos de forma separada (Klein, 1952/1991a) -, seja no caso da dinâmica própria da posição depressiva - em que o amor e o ódio são integrados à pessoa e aos objetos (Klein, 1952/1991a).

É, justamente, na posição depressiva que Melanie Klein considera que a criança já está vivendo num cenário edípico:

A ansiedade e a culpa acrescentam um poderoso impulso em direção ao início do complexo de Édipo, pois elas aumentam a necessidade de externalizar (projetar) figuras más e internalizar (introjetar) figuras boas; de ligar desejos, amor, sentimentos de culpa e tendências reparadoras a alguns objetos, e ódio e ansiedade a outros; de encontrar representantes de figuras internas no mundo externo (Klein, 1952/1991a, p. 73).

Mais ainda: para Klein, nesse momento, as necessidades do bebê o levam tanto a procurar novos objetos quanto novos alvos, ou seja, as relações de objetos deixam de ser marcadas pelo modelo oral para encaminharem-se em direção aos desejos genitais. Todas essas tendências caracterizam e impulsionam o processo de formação de símbolos, levando a criança de um objeto a outro, num processo de sublimação e de substituição de objetos (objeto $\mathrm{A}=$ objeto $\mathrm{B}=$ objeto $\mathrm{C}$ ), estabelecendo o que ela denomina uma equação simbólica. É esse processo que leva a criança à formação do símbolo e à constituição de seu ego (Klein, 1952/1991a, p. 73).

Ao falar sobre as primeiras relações, ou melhor, sobre a relação básica e primordial com a mãe (seio), que dá início às relações de objeto, Klein acentua o fato de essa relação ser acompanhada de um sentimento de inveja, o que gera, inevitavelmente, angústia (Klein, 1957/1991b). Essa angústia - gerada por causa da deflecção da pulsão de morte ou pelo fato de que, por mais satisfatório que seja o encontro da mãe com a criança (no ato de dar de mamar, por exemplo), esta situação jamais teria a capacidade de reproduzir o estado de plenitude experimentado dentro do útero, o que implicaria o sentimento de que o seio, ainda que bom, guarda algo para si - coloca em marcha mecanismos de defesa. Caso esse sentimento de inveja se apresente de forma demasiadamente significativa - por características da criança ou falha ambiental -, para uma criança que tem, então, mais ou menos força egoica para lidar com esse tipo de situação, poderá ocorrer que ela se defenda inibindo ou evitando as próprias relações de objeto, levando, no extremo, a um estado de negação de qualquer relação (como parece ser o caso do autismo).

No seu artigo "A importância da formação de símbolos no desenvolvimento do ego", Klein (1930/1996) afirma que foi justamente a fragilidade de Dick, ante a angústia derivada de suas relações objetais iniciais, que acabou por paralisar seu desenvolvimento:

No caso de Dick, havia uma total incapacidade do ego para suportar ansiedade, de ordem aparentemente constitucional. A zona genital entrara em ação muito cedo; isso causou uma identificação prematura e exagerada com o objeto atacado, e contribuiu para a defesa igualmente prematura contra o sadismo. O ego parou de desenvolver a vida de fantasia e de estabelecer uma relação com a realidade (Klein, 1930/1996, p. 225).

Como resultado dessa situação, em que Dick se protegeu evitando relacionar-se com a realidade, ocorreu uma grande inibição nos tipos de objeto com os quais era possível relacionar-se, prejudicando significativamente o processo de constituição de símbolos, tornando-o indiferente à maioria 
dos objetos e brinquedos, ainda que Dick mantivesse seu interesse por trens e estações (Klein, 1930/1996).

Para Klein, a ansiedade, que entra em jogo nas relações iniciais do bebê com os objetos (seio, mãe, pai etc.), não é apenas um fator que inibe a criança e sua capacidade para relacionar-se, mas corresponde também a um fator importante que levaria a criança a procurar outros objetos, sendo, pois, fundamental para a constituição da rede simbólica (numa busca que leva a outros objetos, estabelecendo a cadeia simbólica). É porque surge a angústia nas relações da criança com seus objetos que ela procuraria substituir esses objetos por outros similares, levando-a a estabelecer uma equação que desembocaria na constituição de símbolos: "Melanie Klein demonstra que os primeiros modos de formação de símbolos, equações simbólicas e identificações formam o fundamento da relação com o mundo externo" (cf. "nota explicativa" dos editores em Klein, 1930/1996, p. 249250). Consequentemente, esse processo levaria a criança a constituir um mundo simbólico como modo de estabelecer suas relações com objetos e, desenvolvendo suas relações com os outros, constituir-se como ser de cultura.

Quando isso falha, quando a angústia advém de maneira insuportável para o eu (já presente, de alguma forma, desde o início), ocorrem outros mecanismos de defesa que podem levar a situações extremas de recusa do mundo, do afeto e do contato. Quando Melanie Klein interpreta as dinâmicas edípicas de Dick, referindo-se ao trem que entra no túnel (Dick que entra na mamãe), ela faz com que a angústia reapareça e obrigue a criança a procurar outro modo de lidar com a angústia: ao invés de defender-se, inibindo-se ou inibindo sua relação com o mundo, Dick procura um objeto substituto:

Isso significava, porém, que a elaboração da ansiedade estava partindo do estabelecimento de uma relação simbólica com as coisas e os objetos. Ao mesmo tempo, os impulsos epistemofílicos e agressivos do menino entraram em ação. Cada avanço trazia a liberação de novas quantidades de ansiedade e fazia com que Dick se afastasse, até certo ponto, das coisas com as quais tinha estabelecido uma relação afetiva, mas que agora se tornavam objetos de ansiedade. Ao fazer isso, ele se voltava para novos objetos, e seus impulsos agressivos e epistemofílicos agora se dirigiam a novas relações afetivas (Klein, 1930/1996, p. 259).

Ao considerar essa dinâmica, parece ficar claro que o método de tratamento psicanalítico de Klein tem, na análise das relações objetais geradoras de angústia, o seu objetivo, a fim de que a angústia produza um tipo de defesa que leve a outras relações, bem como ao desenvolvimento do ego em função de uma série de mecanismos de projeções e introjeções. A sequência esperada, para todos os tipos de pacientes (independente de serem crianças ou adultos, neuróticos ou psicóticos), seria: ao interpretar a relação de objeto que causa angústia (diretamente ou na transferência), esta se apresenta novamente; isso levaria o paciente a defender-se, procurando outros objetos similares ao primeiro, e a relação com novos objetos diminuiria a intensidade da angústia; esse ciclo, retomado inúmeras vezes, ampliaria o conjunto de relações possíveis da criança, levando-a à relação com os outros, à vida em grupo e à vida simbólica da cultura; isso proporcionaria o enriquecimento e fortalecimento do ego, por processos de projeção e introjeção.

O desenvolvimento do eu, para Klein, corresponde a um longo processo de identificações, projeções e introjeções, estabelecidas nas relações com os objetos tanto na fase esquizoparanoide quanto na depressiva. Seguindo o decurso que ocorreria com a construção das equações simbólicas, também haveria o enriquecimento do eu com a diversidade das identificações (projeções e introjeções) vividas nas relações com os objetos. Ou seja, seguindo o título do artigo de Klein, é pela formação de símbolos (construção da equação simbólica) que o eu se desenvolve. Sendo assim, a entrada do homem na vida grupal e cultural corresponde a uma expansão da equação simbólica, tal como Klein apresentou: um processo de sublimação da sexualidade, impulsionado pela angústia nas relações com objetos.

\section{Winnicott e a raiz do símbolo nos fenômenos transicionais}

Para Winnicott (1988/1990), ao nascer, o bebê não tem nenhuma possibilidade de reconhecer uma realidade não self, ou seja, não tem condições maturacionais para estabelecer relações com objetos que ele reconheceria como externos a ele. A crítica que Winnicott faz a Klein, por exemplo, quando comenta a questão do sentimento de inveja, presente nas relações objetais no início do processo de desenvolvimento, explicita que esse tipo de relação exigiria uma maturidade (de organização do ego no sujeito) que não pertence ao bebê, dado que o sentimento de inveja implica que um objeto, reconhecido como externo, possa ter qualidades ou propriedades que o indivíduo constata não estar nele mesmo, admitindo-as como pertencendo ao objeto externo (Winnicott, 1994). Segundo Winnicott, no início, o bebê não existe como uma unidade díspar do ambiente, enquanto um ego que poderia, então, propriamente, relacionar-se com objetos: "Neste estágio, a unidade é o conjunto ambiente-indivíduo (ou um nome mais adequado que se lhe possa dar), unidade da qual o novo indivíduo é apenas uma parte" (Winnicott, 1988/1990, p. 153-154).

Sendo extremamente imaturo, o bebê é pressionado por suas necessidades existenciais (tanto as instintuais como as relacionais) a buscar algo que ele não sabe o que é; no entanto, como nada existe para além dele, o que ele procura é, por assim dizer, algo nele mesmo. Winnicott afirma que, no início, o bebê, no estado excitado, está preparado para encontrar algo em algum lugar, mas sem saber o quê. Quando o ambiente, numa comunicação profunda e sutil com o bebê, 
fornece aquilo que atende às suas necessidades, este vive a experiência ilusória de que criou um objeto adequado às suas necessidades. Winnicott explicita que, nessa situação inicial, "o bebê está pronto para criar, e a mãe torna possível para o bebê ter a ilusão de que o seio, e aquilo que o seio significa, foi criado pelo impulso originado na necessidade" (Winnicott, 1988/1990, p. 121).

Do ponto de vista do observador, o mundo é oferecido ao bebê, mas, do ponto de vista do bebê, ele é criado. A adaptação ambiental suficientemente boa fornece ao bebê a ilusão de que foi ele mesmo, por suas próprias necessidades, quem criou os objetos de que necessita. Mais ainda: o bebê parece viver a experiência de que os objetos advêm da sua necessidade - tal como o calor vem do fogo, para usar uma analogia que fornece um conteúdo intuitivo ao que se está aqui considerando a experiência do bebê. Diz Winnicott:

A adaptação da mãe às necessidades do bebê, quando suficientemente boa, dá a este a ilusão de que existe uma realidade externa correspondente à sua própria capacidade de criar. Em outras palavras, ocorre uma sobreposição entre o que a mãe supre e o que a criança poderia conceber (Winnicott, $1955 / 2000$, p. 27).

É o ambiente (a mãe ou quem faz as vezes da mãe) que - interpretando o que o bebê precisa - oferece os objetos a serem encontrados de forma adequada. Para o bebê, os objetos advêm diretamente de suas necessidades, como se delas fossem criados, ainda que, do ponto de vista do observador, uma miríade de adaptações do ambiente estejam em jogo. De sua perspectiva, o bebê mama em si mesmo, num seio que faz parte dele (Winnicott, 1955/2000), num mamilo e obtendo um leite que foram produzidos pela sua necessidade, como que gerados por ela (Winnicott, 1988/1990). Não há dúvida de que, para os observadores dessa situação, há uma divergência entre o que foi criado e o que foi oferecido, mas, para o bebê, isso não tem importância: "sabemos que aquilo que o bebê criou não foi aquilo que a mãe forneceu, mas a mãe, por sua adaptação extremamente delicada às necessidades (emocionais) do bebê, está em condições de permitir que ele tenha esta ilusão" (Winnicott, 1988/1990, p. 121).

É a essa situação, na qual os objetos surgem como decorrência das necessidades do bebê - sem que ele tenha nem mesmo que fazer a ação (sentida como uma ação como tal) de criar os objetos -, que Winnicott caracteriza como sendo uma área ou experiência de ilusão de onipotência. Para ele, o bebê vive numa área de ilusão (de onipotência), na qual, sem poder representar propriamente os objetos, encontra-os tanto como uma criação sua quanto como algo que o ambiente fornece (Winnicott, 1953/1975a).

O objeto com o qual o bebê se relaciona, de sua perspectiva, nesse momento, não pode ser, de maneira alguma, símbolo de algum outro; ao contrário, ele é o objeto único, criado com base na singularidade do aqui e agora da necessidade do bebê. Winnicott denominou-o objeto subjetivo.
O objeto é o bebê, por assim dizer, mas também é necessário reconhecer que não há, ainda, uma unidade inicial com a qual uma relação com objetos possa ocorrer. Paradoxalmente, pode-se afirmar que, no início, não há um objeto externo nem um eu. Será na ação criativa do bebê, sustentada pelo ambiente, que surgirá, ao mesmo tempo, a experiência do si-mesmo e o encontro com o objeto (subjetivo, criado pelo bebê), estabelecendo-se, então, um tipo de relação entre esse si-mesmo e o objeto assim criado na sua singularidade.

Para visualizar um esquema gráfico que expressa esse fato, é como traçar a curva que dá, ao mesmo tempo, o côncavo e o convexo, o si-mesmo e o objeto subjetivo, ligandoos como uma criação do si-mesmo em direção a esse objeto. Pergunta: quem faz o traço? Resposta: é o bebê, com a ação adaptativa adequada do ambiente. Finda a necessidade, tanto o si-mesmo quanto o objeto deixam de ter existência propriamente dita. São a continuidade e a repetição desse tipo de experiência que, pouco a pouco, fornecerão elementos tanto para que esse si-mesmo possa ir se integrando (unindo essas experiências) quanto reconhecendo sinais de exterioridade nos objetos. A dinâmica que leva do mundo subjetivo ao mundo objetivamente percebido exigiria que se esclarecesse o que ocorre nas fases que Winnicott denominou desilusão, transicionalidade, uso do objeto e eu sou.

Certamente, nesse momento, não há lugar para que um objeto seja símbolo de outro; não há, pois, nessa fase do amadurecimento, relações simbólicas. Somente a longa jornada que levará ao reconhecimento de objetos externos é que tornará possível a existência de objetos que são símbolos de outros objetos.

Não é o caso, aqui, de descrever, passo a passo, como a realidade externa passa a ter existência como algo separado do indivíduo - ou seja, considerando um eu que se relaciona com objetos externos (sejam eles parciais ou totais) -, mas, sim, de explicitar que entre esse momento inicial e o que se encontra quando há um eu integrado, diferenciando mundo externo de mundo interno, há uma fase intermediária, na qual os objetos com os quais o bebê se relaciona são ao mesmo tempo, paradoxalmente, criados e encontrados. A esses objetos Winnicott caracteriza como transicionais, e a eles credita as raízes das relações com símbolos. Trata-se, pois, de explicar em que sentido os objetos transicionais são e não são, ao mesmo tempo, símbolos de algum outro objeto.

Com a continuidade do processo de amadurecimento, a onipotência é perdida ou destruída, mas a ilusão de relacionar-se com um mundo que diz respeito ao bebê, um mundo que ele criou e pode operar com base nele mesmo, permanece: "Gradualmente, surge uma compreensão intelectual do fato de que a existência do mundo é anterior à do indivíduo, mas o sentimento de que o mundo foi criado pessoalmente não desaparece" (Winnicott, 1955/2000, p. 28). No processo de amadurecimento, aquilo que era o objeto totalmente subjetivo é materializado num objeto, sem destruir, no entanto, o fato de que ele é criado pelo bebê, tal como se pode visualizar num esquema feito pelo próprio autor, no qual ele desenha uma figura fechada (um objeto) entre o bebê e o seio 
(ou mãe) com o qual se relaciona (Winnicott, 1953/1975a).

Os objetos transicionais são, ao mesmo tempo, criados e encontrados, constituindo um paradoxo simplesmente aceito, tanto para o bebê quanto para o observador externo. Esse paradoxo não é algo que deva ser solucionado, mas vivido como tal; qualquer atitude que tente resolvê-lo acaba por destruí-lo em sua natureza de fenômeno transicional (Winnicott, 1953/1975a).

Esse objeto corresponde a algo que o bebê tem, que não é propriamente ele e que é dotado de realidade externa; é a primeira possessão "não-eu". Não se trata do primeiro objeto, dado que os objetos transicionais não podem ser caracterizados propriamente como um objeto externo, mas sim do primeiro modo de relação com algo não-eu e, paradoxalmente, ainda eu. A esse respeito, explicita Winnicott (1955/2000, p. 15): "Não estou estudando especificamente o primeiro objeto das relações de objeto. Estou interessado na primeira possessão e na área intermediária entre o subjetivo e aquilo que é objetivamente percebido".

Pode-se dizer que o objeto transicional simboliza algum objeto subjetivo (a mãe), mas Winnicott insiste no fato de que esse objeto é importante não apenas porque está no lugar da mãe, fazendo as vezes dela, mas porque tem uma realidade própria que advém da sua materialidade e do fato de ser criado pelo indivíduo:

É verdade que a ponta do cobertor (ou o que quer que seja) é simbólica de algum objeto parcial, tal como o seio. No entanto, o importante não é tanto seu valor simbólico, mas sua realidade. $\mathrm{O}$ fato de ele não ser o seio (ou a mãe), embora real, é tão importante quanto o fato de representar o seio (ou a mãe) (Winnicott, 1955/2000, p. 19).

A questão a ser esclarecida é a de saber que tipo de símbolo é este, que, ao mesmo tempo, é um substituto da mãe e tem uma realidade própria (também advinda pelo fato de ser uma criação do bebê). Se o objeto transicional tem valor afetivo para o bebê por estar no lugar de algum objeto subjetivo (a mãe, o seio), deve-se também lembrar que esse objeto só mantém seu valor enquanto tal se a mãe for uma presença para o bebê (seja corporal, seja na sua mente) (Winnicott, 1967/1975b).

O que dá valor ao objeto transicional é, por assim dizer, o objeto externo que ele substitui, e do qual ele depende para garantir a sua existência. Winnicott afirma que o bebê ou a criança pode usar o objeto transicional como um "objeto interno", ou seja, como um objeto que substitui internamente um objeto externo, desde que o objeto externo possa efetivamente conferir valor ao objeto transicional: "este objeto interno [o objeto transicional tomado no seu aspecto interno, para o bebê ou a criança] depende, quanto a suas qualidades, da existência, vitalidade e comportamento do objeto externo" ( Winnicott, 1955/2000, p. 24).

Retomando a definição pierciana de símbolo, pode-se dizer que o objeto transicional é símbolo de um objeto caso esse objeto (seu referente) esteja presente, conferindo-lhe valor. Sendo assim, o objeto transicional só pode ser símbolo da mãe se esta estiver presente (fisicamente ou na mente do bebê). Caso a mãe desapareça (morte, ausência por tempo maior que o bebê possa tolerar, ou qualquer outro tipo de transformação que faça com que o bebê não reconheça mais a presença da mãe), o objeto transicional tende a morrer enquanto tal. A esse respeito, esclarece Winnicott (1955/2000, p. 24): "O fracasso deste [objeto externo, a mãe ou algo similar] em alguma função essencial leva indiretamente à morte, ou a uma qualidade persecutória do objeto".

No momento em que se tem o início da existência dos fenômenos transicionais, a criança ainda não tem uma clara distinção entre o que é externo e o que é interno, o que é criado e o que é encontrado, entre as suas fantasias e os fatos eles mesmos. Será a conquista dessas diferenciações que tornará possível as relações simbólicas propriamente ditas, não antes disso: "Quando o simbolismo é empregado, o bebê já está claramente distinguindo entre fantasia e fato, entre objetos internos e objetos externos, entre criatividade primária e percepção" (Winnicott, 1955/2000, p. 19).

Os objetos transicionais correspondem, pois, ao momento de origem e à raiz do processo de simbolização, marcando a passagem entre a relação com objetos subjetivos para com objetos objetivamente percebidos. Winnicott diferencia os fenômenos iniciais, nos quais os objetos, para o bebê, têm a natureza de serem subjetivos, dos fenômenos mais tardios do processo de amadurecimento, nos quais a criança conquistou a integração numa unidade, tornando possível distinguir o dentro e o fora, o mundo interno do mundo externo, podendo, portanto, fazer com que o indivíduo possa reconhecer e relacionar-se com objetos externos (objetos valorados e reconhecidos como pertencentes ao mundo externo da criança).

Entre um polo e outro, há um conjunto de modos de relação com a realidade que não podem ser nomeados subjetivos nem objetivos, mas que fazem a conexão e a passagem entre estes dois modos (subjetivo, objetivo) de relação com a realidade: os objetos e fenômenos transicionais. A constituição de um símbolo, ou seja, de um objeto que está no lugar de outro, substituindo-o, só será plenamente realizada quando o objeto puder ser reconhecido como externo. No entanto, a raiz ou origem do processo de constituição do símbolo está, para Winnicott, no campo dos objetos e fenômenos transicionais (Winnicott, 1955/2000).

Cabe ainda notar que a transicionalidade, enquanto raiz do simbolismo, não corresponde somente a um momento de passagem, que teve início nas fases mais primitivas do amadurecimento e depois foi ultrapassado ou substituído por outros modos de relação com a realidade; ele permanece como uma dinâmica presente que também corresponde a um dos aspectos da dinâmica relacional que faz com que os símbolos possam ter valor e existir enquanto tais. Ao falar sobre o destino dos objetos transicionais, Winnicott considera que, com o amadurecimento do indivíduo, esse objeto não é reprimido nem guardado num interior, não é esquecido nem pranteado, mas, pouco a pouco, perde o seu significado, 
perde sua importância, dado que aquilo que era investido no objeto transicional passa a ser difusamente investido no mundo da vida cultural e da relação com os outros (Winnicott, 1955/2000).

Ao referir-se à cultura como o lugar em que vivemos, Winnicott esclarece que a experiência cultural nada mais é do que um tipo de expansão dos fenômenos transicionais. Conceitualmente, ele afirma que o espaço, no qual podem surgir objetos que não pertencem propriamente ao mundo externo nem ao mundo interno denominado por ele espaço potencial, é tanto o espaço onde surgem os objetos transicionais como aquele em que se dá a vida cultural (e, portanto, a vida simbólica compartilhada): "O lugar em que a experiência cultural se localiza está no espaço potencial existente entre o indivíduo e o meio" (Winnicott, 1967/1975b, p. 139).

Uma das características principais dos objetos transicionais é o fato de eles serem criados, logo, de eles manterem o caráter da ilusão de "criar o mundo em que se vive". Esse aspecto criativo relaciona-se com a atividade do brincar espontâneo. Se, por um lado, é no brincar que o indivíduo encontra a si mesmo - "É no brincar, e somente no brincar, que o indivíduo, criança ou adulto, pode ser criativo e utilizar sua personalidade integral; e é somente sendo criativo que o indivíduo descobre o eu (self)" (Winnicott, 1971/1975d, p. $80)$-, por outro, é no brincar e na criatividade que ele reconhece que a vida vale a pena de ser vivida. Para Winnicott, a vida que vale a pena é a vivida pelo verdadeiro self; mas se é o falso self que se estabelece enquanto um modo de ser e de relacionar-se com o mundo, certamente haverá uma sensação de inutilidade ou futilidade da vida (Winnicott, 1955/1978).

É também nesse brincar que a vida cultural é constituída como algo compartilhável, para o qual o indivíduo contribui para a sociedade, ao mesmo tempo em que realiza algo para e em si mesmo. A brincadeira, ou seja, a criatividade associada à construção e relação com objetos que estão, ao mesmo tempo, fora e dentro do indivíduo, objetos que guardam semelhança com a natureza dos objetos transicionais, são, para Winnicott (1971/1975d, p. 147), o fundamento da vida cultural: "Para mim, o brincar conduz naturalmente à experiência cultural e, na verdade, constitui seu fundamento". A cultura, no seu sentido amplo, é o lugar, na saúde, deste encontro mútuo entre o si-mesmo e a vida com o outro; como explicita Winnicott (1967/1975b, p. 137-138), a cultura corresponde ao "fundo comum da humanidade, para o qual indivíduos e grupos podem contribuir, e do qual todos nós podemos fruir, se tivermos um lugar para guardar o que encontramos".

Os objetos transicionais podem ser considerados os primeiros objetos símbolos com os quais a criança se relaciona, mas têm valor e existência para ela pelo investimento afetivo neles colocado; mais do que isso, eles têm valor porque são uma criação que diz respeito à própria atividade do brincar, sinônimo do gesto criativo ou da espontaneidade. Segundo Winnicott, há uma linha de desenvolvimento que vai dos objetos subjetivos aos objetos transicionais, destes para o brincar e o brincar compartilhado, desembocando na vida cultural. Sobre isso, esclarece Winnicott (1968/1975c, p. 76):
"Há uma evolução direta dos fenômenos transicionais para o brincar, do brincar ao brincar compartilhado, e deste para as experiências culturais". Pode-se dizer que, quando uma criança usa um objeto transicional, sua primeira possessão não-eu, se assiste ao primeiro uso de um símbolo, como também a suas primeiras experiências em poder brincar e fazer uso da brincadeira. Isso não é propriamente uma atividade projetiva ou expressiva, é mais fundamental: é a realização da experiência de ser, a única na qual é possível encontrar a si mesmo e ao outro.

Retoma-se, aqui, uma citação longa de Adam Phillips comentando a especificidade da perspectiva desenvolvida por Winnicott, opondo-se à teoria da cultura tal como Freud a formulou:

Enquanto Freud se preocupava com as enredadas possibilidades de satisfação pessoal de cada indivíduo, para Winnicott essa satisfação seria apenas parte do panorama mais amplo das possibilidades para autenticidade pessoal do indivíduo, o que ele chamará de "sentir-se real". Na escrita de Winnicott, a cultura pode facilitar o crescimento, assim como o pode a mãe; para Freud, o homem é dividido e compelido, pelas contradições de seu desejo, na direção de um envolvimento frustrante com os outros. Em Winnicott, o homem só pode encontrar a si mesmo em sua relação com os outros, e na independência conseguida através do reconhecimento da dependência. Para Freud, em resumo, o homem era o animal ambivalente; para Winnicott, ele seria o animal dependente, para quem o desenvolvimento - a única "certeza" de sua - era a tentativa de se tornar "separado sem estar isolado". Anterior à sexualidade como o inaceitável, havia o desamparo. A dependência era a primeira coisa, antes do bem e do mal (Phillips, 2007, p. 29).

É coerente com a posição de Winnicott afirmar que o processo de simbolização, o próprio processo de entrada do homem na cultura, partilhando os símbolos de uma comunidade, é uma expansão da atividade da brincadeira. É por isso que ele considera a brincadeira como um aspecto universal da natureza humana, e a psicanálise como uma forma especializada do brincar, afirmando:

O brincar facilita o crescimento e, portanto, a saúde; o brincar conduz aos relacionamentos grupais; o brincar pode ser uma forma de comunicação na psicoterapia; finalmente, a psicanálise foi desenvolvida como forma altamente especializada do brincar, a serviço da comunicação consigo mesmo e com os outros (Winnicott, 1968/1975c, p. 63).

Ao caracterizar a psicanálise como um tipo de brincar específico, Winnicott também diz qual é o télos, o horizonte e o objetivo para o qual uma análise deve tender: por um 
lado, o reconhecimento de que a psicoterapia (analítica ou não) ocorre na sobreposição das áreas do brincar do paciente e do analisa, e, por outro, quando ocorre de o paciente estar doente a ponto de não poder brincar, a explicitação da conquista da capacidade de brincar como um dos objetivos do tratamento psicoterápico.

Esse brincar corresponde à possibilidade de o paciente agir com base em seu si-mesmo verdadeiro, adaptar-se e compartilhar do mundo e das relações com o mundo (simbolicamente ou não), sem perder em demasia a sua espontaneidade (o mesmo poderia ser dito sobre o analista): "Quando existe um brincar mútuo, então a interpretação, segundo os princípios psicanalíticos aceitos, pode levar adiante o trabalho terapêutico. Esse brincar tem de ser espontâneo, e não submisso ou aquiescente, se é que se quer fazer psicoterapia" (Winnicott, 1971/1975e, p. 75-76). É interessante, nesse sentido, em que se pretende caracterizar a natureza da atividade do brincar, que Phillips (1988) comente que o oposto do brincar não corresponda ao trabalhar, mas à coerção.

O processo analítico - processo que leva ao amadurecimento, entendendo este como uma expansão das áreas de relacionamento, expansão do espaço potencial e dos objetos (simbólicos ou não) com os quais o indivíduo pode se relacionar - deve, pois, fornecer os cuidados ambientais para que esse tipo de gesto espontâneo que caracteriza a brincadeira, esse tipo de criatividade, possa ocorrer. Em oposição a Melanie Klein, a reação à angústia como um mecanismo de defesa que poderia levar a outra relação de objeto nada mais seria do que uma ação reativa, portanto, desprovida da qualidade essencial que caracteriza a criação com base em si mesmo. É nesse sentido que Winnicott afirma que toda ação apenas reativa aniquila o ser: "A alternativa a ser é reagir, e reagir interrompe o ser e o aniquila" (Winnicott, 1960/1983a, p. 47).

Com base em sua teoria do brincar, Winnicott pode caracterizar no que consiste o processo terapêutico, afirmando, então, que a base do brincar está num tipo de experiência livre, sem forma predefinida (à qual ele denominará um funcionamento amorfo), e que cabe ao psicoterapeuta "propiciar oportunidade para a experiência amorfa e para os impulsos criativos, motores e sensórios, que constituem a matériaprima do brincar" (Winnicott, 1971/1975e, p. 93). Mais que isso, ele reconhecerá nesse fenômeno da brincadeira a própria essência do que seria a natureza humana:

É com base no brincar que se constrói a totalidade da existência experiencial do homem. Não somos mais introvertidos ou extrovertidos. Experimentamos a vida na área dos fenômenos transicionais, no excitante entrelaçamento da subjetividade e da observação objetiva, e numa área intermediária entre a realidade interna do indivíduo e a realidade compartilhada do mundo externo aos indivíduos (Winnicott, 1971/1975e, p. 93).

\section{Diferenças entre Klein e Winnicott}

Pode-se agora, ao final, sintetizar as diferenças fundamentais entre Klein e Winnicott no que diz respeito à direção do processo analítico e ao processo de simbolização.

Para Klein, a análise deve interpretar as relações de objeto em termos de suas dinâmicas da posição esquizoparanoide (o amor e o ódio vividos separadamente, com a cisão dos objetos e do próprio eu, seus mecanismos projetivos e introjetivos, idealizações, os impulsos amorosos e os destrutivos dirigidos a esses objetos) e da posição depressiva (o amor e o ódio vividos de forma unificada, o reconhecimento dos impulsos amorosos e destrutivos no eu, agora unificado, e agindo nos objetos, estes também unificados como objetos totais, gerando sentimentos de culpa e desejos de reparação pelos impulsos destrutivos dirigidos contra os objetos amados, com todas as dificuldades e necessidades de reparação que tal integração significa). As relações com os objetos, tanto numa dinâmica como noutra (esquizoparanoide e depressiva), seriam geradoras de angústia e de um mecanismo de defesa do ego que impulsionaria o indivíduo a procurar objetos substitutos, visando a relações menos angustiantes. A substituição de objetos por outros de valor semelhante constituem, para Klein, equações simbólicas que levam à possibilidade de expansão das relações com os objetos, o que desemboca na possibilidade da relação com os outros e com todos os bens culturais.

De acordo com Klein, o objetivo último do tratamento psicanalítico corresponde à integração da personalidade do paciente, que implica em unir, na personalidade total do paciente, seus impulsos amorosos e destrutivos, resultando numa diminuição da inveja e do medo da inveja, e no estabelecimento mais fortalecido da capacidade de amar, ou seja, a edificação de uma confiança maior nas forças construtivas e reparadoras. Trata-se de, no fim da análise, ter conseguido reconhecer e tolerar as próprias limitações, estabelecendo relações de objeto marcadas por uma percepção mais clara e diferenciada do que é a realidade interna e externa (Klein, 1957/1991b).

O processo analítico, que leva a esse estado de organização do ego e dos modos de relação objetal do indivíduo com o mundo, é feito por meio da interpretação da angústia que subjaz todas as relações objetais, tornando possível que a ansiedade, advinda do medo de que os sentimentos hostis destruam os objetos amados, diminua, uma vez que esses sentimentos podem ser mais conhecidos, mais bem dimensionados e, assim, integrados à personalidade do paciente (Klein, 1957/1991b). Sendo assim, a análise da angústia leva o paciente a desenvolver e expandir a equação simbólica que encadeia objetos substitutivos, num processo de sublimação, partilhamento e distribuição da angústia nesses objetos; com isso, há a possibilidade da relação simbólica com os objetos no mundo.

O fim de análise leva, portanto, à integração do indivíduo e dos objetos, agregando os impulsos amorosos e destrutivos no estabelecimento da vida cultural assentada nas 
relações marcadas por objetos que podem ser símbolos de objetos mais primitivos e, nesse sentido, mais livres das angústias e mecanismos de defesa que poderiam obliterar e inibir essas relações.

O objetivo de uma análise, segundo Winnicott, é próximo ao enunciado por Melanie Klein, ainda que ele o descreva incluindo outros aspectos do que considera ser um indivíduo saudável. Sobre o que é um indivíduo saudável, esclarece Winnicott:

A vida de um indivíduo são se caracteriza mais por medos, sentimentos conflitantes, dúvidas, frustrações do que por seus aspectos positivos. O essencial é que o homem ou a mulher se sintam vivendo sua própria vida, responsabilizando-se por suas ações ou inações, sentindo-se capazes de atribuírem a si o mérito de um sucesso ou a responsabilidade de um fracasso. Pode-se dizer, em suma, que o indivíduo saiu da dependência para entrar na independência ou autonomia (Winnicott, 1971/1989, p. 30).

Esse modo de afirmar o objetivo do tratamento analítico (integração para tornar-se uma pessoa inteira responsável por suas ações) é pensado em termos das relações com o ambiente. Nunca se trata, para Winnicott, de uma relação apenas da perspectiva da dinâmica interna do indivíduo, mas de um estar-com que caracteriza ter um lugar compartilhado com o outro para viver. $\mathrm{O}$ autor afirma isso baseado em sua concepção de que o amadurecimento é uma linha que vai da dependência para a independência, sabendo, no entanto, que a independência nunca é absoluta, mas deve integrar a vida social e a vida cultural (Winnicott, 1965/1983c).

Um ser humano maduro, para Winnicott, por um lado, guardou a ilusão de que o mundo em que ele vive é criado por ele, mas, por outro, reconhece um mundo objetivamente dado, como algo fora dele, do qual depende e se adapta sem perda em demasia da sua espontaneidade, e do qual cuida, não por obrigação ou medo de punição, retaliação ou gratidão, mas porque isso também significa ser, cuidar de si e do lugar onde se pode viver: "A maturidade do ser humano é uma palavra que implica não somente crescimento pessoal, mas também socialização" (Winnicott, 1965/1983c, p. 80). A vida saudável corresponde, pois, à possibilidade de uma pessoa poder identificar-se com outras e com grupos e identidades sociais dos mais variados graus, sem perder, no entanto, a sua individualidade ou espontaneidade: "o adulto é capaz de satisfazer suas necessidades pessoais sem ser antissocial, e, na verdade, sem falhar em assumir alguma responsabilidade pela manutenção ou pela modificação da sociedade em que se encontra" (Winnicott, 1965/1983c, p. 80).

Trata-se de, retomando a questão da brincadeira como um aspecto universal da natureza humana, de conseguir, no tratamento analítico, levar o paciente à possibilidade de brincar, ou seja, à possibilidade de poder agir sobre o mundo por si mesmo, compartilhando de um mundo que é, ao mesmo tempo, criado e encontrado por ele. Ao longo do tratamento, com o paciente podendo confiar no processo analítico, o que significa previsibilidade e comunicação com o ambiente, ou seja, com o analista, ele pode fazer toda uma série de experimentações em termos de um si-mesmo que age por si mesmo. A esse respeito, explicita Winnicott: “o paciente, [nesta fase conquistada no processo analítico] agora independente, começa a se revelar e afirmar suas características individuais, começando o paciente a ver como natural o sentimento de existir por si mesmo" (Winnicott, 1965/1983b, p. 154).

Esses objetivos correspondem, por sua vez, ao processo que vai da relação não simbólica com os objetos subjetivos, passando pelas raízes do simbolismo no objeto transicional e expandindo-se (guardando características dos fenômenos transicionais) em direção ao mundo cultural compartilhado - sem perda demasiada da espontaneidade. O processo de simbolização não corresponde a um mecanismo de defesa contra uma angústia na relação objetal, mas à expansão da relação não angustiante com os objetos subjetivos e objetos transicionais, garantida pela sustentação ambiental.

O processo analítico procura retomar as condições de sustentação e comunicação ambiental, nas quais estão envolvidas relações objetais, para que o amadurecimento, ou seja, a expansão das relações com o mundo, possa ocorrer. É nesse sentido que Winnicott (1965, p. 132) diz:

A criança precisa sair do colo da mãe, mas não daí para o espaço sideral; esse afastamento deve dar-se em direção a uma área maior, mas ainda sujeita a controle: algo que simbolize o colo que a criança abandonou. Uma criança mais velha foge de casa, mas só até a cerca do jardim. A cerca simboliza agora aquele aspecto do holding mais estreito que acabou de ser rompido: a casa, digamos. Mais tarde, a criança elabora tudo isso quando vai à escola e entra em relação com grupos fora do lar. Cada um desses grupos representa uma fuga de casa; mas, ao mesmo tempo, todos simbolizam esse lar que foi deixado para trás e, na fantasia, destruído.

\section{Considerações finais}

Em síntese, enquanto para Klein a análise necessita ser movida pela angústia, para Winnicott é a confiabilidade ambiental que sustenta e dá segurança ao si-mesmo, e a conquista da possibilidade de brincar (no sentido winnicottiano da palavra) é aquilo que, como télos e motor do tratamento, pode levar o paciente a encontrar um lugar pelo qual viver, num agir sem perda demasiada da espontaneidade em direção à expansão das relações com o mundo. As angústias que daí derivam ou podem derivar constituem efeitos que exigirão, certamente, uma administração, mas não são elas que levam ou proporcionam outras relações de objeto propriamente ditas. 
Para Klein, a base do processo de simbolização está na dispersão e deslocamento da angústia presente nas relações objetais em direção à sublimação das pressões instintuais, enquanto, para Winnicott, esse processo deriva da expansão dos fenômenos transicionais, como expressão de si mesmo no criar e encontrar o mundo.

\section{Referências}

Abram, J. (2008). Donald Woods Winnicott (18961971): A brief introduction. International Journal of Psychoanalysis, 89(6), 1189-1217.

Fulgencio, L. (2007). Paradigmas na história da psicanálise. Natureza Humana, 9(1), 97-128.

Klein, M. (1991a). As origens da transferência. In M. Klein, Inveja e gratidão e outros trabalhos (1946-1963) ( L. P. Chaves, Trad., pp. 71-80). Rio de Janeiro: Imago. (Original publicado em 1952)

Klein, M. (1991b). Inveja e gratidão. In M. Klein, Inveja e gratidão e outros trabalhos (1946-1963) (L. P. Chaves, Trad., pp. 207-267). Rio de Janeiro: Imago. (Original publicado em 1957)

Klein, M. (1996). A importância da formação de símbolos no desenvolvimento do ego. In M. Klein, Amor, culpa e reparação e outros trabalhos (1921-1945) (A. Cardoso, Trad., pp. 249-264). Rio de Janeiro: Imago. (Original publicado em 1930)

Loparic, Z. (1997). Winnicott e Melanie Klein: Conflito de paradigmas. In I. F. M. Catafesta (Org.), A clínica e a pesquisa no final do século: Winnicott e a universidade (pp. 43-60). São Paulo: Lemos.

Loparic, Z. (2001). Esboço do paradigma winnicottiano. Cadernos de História e Filosofia da Ciência, 11(2), 7-58.

Peirce, C. S. (1975). Divisão dos signos. In C. S. Peirce, Semiótica (pp. 93-114). São Paulo: Perspectiva.

Phillips, A. (1988). Winnicott. London: Fontana Press.

Phillips, A. (2007). Winnicott. São Paulo: Idéias \& Letras.

Winnicott, D. W. (1965). Família e maturidade emocional. In D. W. Winnicott, A familia e o desenvolvimento individual (M. B. Cipola, Trad., pp. 129-140). São Paulo: Martins Fontes.

Winnicott, D. W. (1975a). Objetos transicionais e fenômenos transicionais. In D. W. Winnicott, $O$ brincar e a realidade (J. O. A. Abreu \& V. Nobre, Trads., pp. 13-44). Rio de Janeiro: Imago. (Original publicado em 1953)

Winnicott, D. W. (1975b). A localização da experiência cultural. In D. W. Winnicott, $O$ brincar e a realidade (J. O. A. Abreu \& V. Nobre, Trads., pp. 133-143). Rio de Janeiro: Imago. (Original publicado em 1967)

Winnicott, D. W. (1975c). O brincar: Uma exposição teórica. In D. W. Winnicott, $O$ brincar e a realidade (J. O. A. Abreu \& V. Nobre, Trads., pp. 59-77). Rio de Janeiro: Imago. (Original publicado em 1968)
Winnicott, D. W. (1975d). A criatividade e suas origens. In D. W. Winnicott, O brincar e a realidade (J. O. A. Abreu \& V. Nobre, Trads., pp. 95-120). Rio de Janeiro: Imago. (Original publicado em 1971)

Winnicott, D. W. (1975e). O brincar: A atividade criativa e a busca do eu (self). In D. W. Winnicott, $O$ brincar e $a$ realidade (J. O. A. Abreu \& V. Nobre, Trads., pp. 79-94). Rio de Janeiro: Imago. (Original publicado em 1971)

Winnicott, D. W.(1978). Aspectos clínicos e metapsicológicos da regressão no contexto psicanalítico. In D. W. Winnicott, Da pediatria à psicanálise (J. Russo, Trad., pp. 374-392). Rio de Janeiro: Francisco Alves. (Original Publicado em 1955)

Winnicott, D. W. (1983a). Teoria do relacionamento paternoinfantil. In D. W. Winnicott, $O$ ambiente e os processos de maturação (I. C. S. Ortiz, Trad., pp. 38-54). Porto Alegre: Artes Médicas. (Original publicado em 1960)

Winnicott, D. W. (1983b). Os objetivos do tratamento psicanalítico. In D. W. Winnicott, $O$ ambiente e os processos de maturação (I. C. S. Ortiz, Trad., pp. 152155). Porto Alegre: Artes Médicas. (Original publicado em 1965)

Winnicott, D. W. (1983c). Da dependência à independência no desenvolvimento do indivíduo. In D. W. Winnicott, O ambiente e os processos de maturação (I. C. S. Ortiz, Trad., pp. 79-87). Porto Alegre: Artes Médicas. (Original publicado em 1965)

Winnicott, D. W. (1989). O conceito de indivíduo saudável. In D. W. Winnicott, Tudo começa em casa (P. Sandler, Trad., pp. 17-30). São Paulo: Martins Fontes. (Original publicado em 1971)

Winnicott, D. W. (1990). Natureza humana (D. L. Bogomoletz, Trad.). Rio de Janeiro: Imago. (Original publicado em 1988)

Winnicott, D. W. (1994). Melanie Klein: Sobre o seu conceito de inveja: I. Resenha de Envy and Gratitude: 1959. In C. Winnicott, R. Shepherd, \& M. Davis (Orgs.), Explorações psicanaliticas: D. W. Winnicott (J. O. A. Abreu, Trad., pp. 338-340). Porto Alegre: Artes Médicas.

Winnicott, D. W. (2000). A posição depressiva no desenvolvimento emocional normal. In D. W. Winnicott, Da pediatria à psicanálise (D. L. Bogomoletz Trad., pp. 355-373). Rio de Janeiro: Imago. (Original publicado em 1955)

Leopoldo Fulgencio é Professor Doutor do Programa de Pós-graduação em Psicologia da Pontifícia Universidade Católica de Campinas.
Recebido: 10/02/2010

$1^{a}$ revisão: 05/01/2011

Aceite final: 17/02/2011 